\title{
Naupliar development of Pseudocyclops sp. (Copepoda: Calanoida: Pseudocyclopidae): description of an unusual set of character states
}

\author{
Frank D Ferrari ${ }^{1}$, Hans-Uwe Dahms ${ }^{2 *}$, Pawana Kangtia ${ }^{3}$, Supawadee Chullasorn ${ }^{3}$ and Mark Schick ${ }^{4}$
}

\begin{abstract}
Background: Naupliar development is known for only one other species of the calanoid taxon Pseudocyclopidae as yet.

Results: Six naupliar stages are described from an as yet unnamed population of Pseudocyclops cultured at the John G. Shedd Aquarium in Chicago, IL. The naupliar body is divided into a deep anterior section and a shallow posterior section, although the posterior section is poorly defined at NI. The posterior section bears a long, thin mediodorsal seta; short thick setae are added during molts to NIII NV. The posterior section does not bear limb buds except for the caudal ramus and is presumed to represent the anal segment of the copepod. Throughout naupliar development, the antennule is five-segmented, a uniquely high number for a calanoid copepod. The distal segment is broadened, and three proximal segments are foreshortened during the molt to NIII, and remain so thereafter. Setae are added dorsally and ventrally to the distal segment during each molt. The naupliar arthrite is a simple, seta-like structure on the coxa of the antenna of all naupliar stages. On the exopod of the antenna, setae are added to the segment adjacent to the proximal one during molts to NIV $\sim$ NVI in a manner consistent with the model of ramal patterning. The gnathobase is added to the coxa of the mandible during the molt to NIV, but its ventral attenuations are lost during the molt to NVI. The endopod of the mandible significantly changes between stages NIII and NIV; setae originate dorsally rather than ventrally on the proximal endopodal segment. These unique changes are reversed during the molt to NVI.
\end{abstract}

Conclusions: Many of these changes have not been reported for any other calanoid. The morphological restoration at NVI is particularly noteworthy.

Keywords: Naupliar development; Pseudocyclops sp; Calanoida; Shedd aquarium

\section{Background}

There are 37 nominal species in the calanoid copepod genus Pseudocyclops Brady, 1872, and Pseudocyclops is the only genus in the family Pseudocyclopidae (Brady 1872). The genus is widely distributed in tropical, subtropical, and temperate waters (Barr 1994) from the coastal zone to the edge of the continental shelf, although individual species are regionally restricted (Andronov 1986). Most species have been collected on or immediately over the seabed (Bowman and González 1961). Almost all species of Pseudocyclops are marine, with only a few reported

\footnotetext{
* Correspondence: hansdahms@smu.ac.kr

${ }^{2}$ Green Life Science Department, College of Convergence, Sangmyung University, 7 Hongij-dong, Jongno-gu, Seoul 110-743, Republic of Korea Full list of author information is available at the end of the article
}

from brackish waters (Baviera et al. 2007, Brugnano et al. 2010). Little is known about their reproductive biology. Information is available for the effect of temperature on egg production, and observations were made of egg care by females (Brugnano et al. 2009). Naupliar development was described for only one species (Costanzo et al. 2004), but some of those results appear contrary to what is known for naupliar development of copepods in general (Ferrari and Dahms 2007). Copepodid development is known for two species (Costanzo et al. 2004, Ferrari et al. 2011b), and studies on copepodid development have proven critical in supporting the hypothesis that the Pseudocyclopidae is the sister group of the remaining gymnoplean families (Ferrari et al. 2011a, b). Given the dearth of information on naupliar development and the 
phylogenetic position of the family, naupliar development of an unnamed species of Pseudocyclops that was introduced into aquaria at the John G. Shedd Aquarium, Chicago, IL, USA is described here.

\section{Methods}

Nauplii of Pseudocyclops sp. were cultivated at the Shedd Aquarium. An aggregation of copepods was removed to a 120-L culture vessel which is about $1 \mathrm{~m}$ tall, and sampled from a drain near the bottom of the vessel after the first, third, fourth, fifth, and seventh week in October and November 2010. Specimens were fixed in approximately $5 \%$ neutralized formalin immediately after capture, transferred to $70 \%$ ethanol, and subsequently transferred to glycerol for slide preparation. For line drawings made with a camera lucida, whole or dissected specimens were examined in glycerol with bright-field or differential interference optics (see Dahms et al. 2009; Ferrari and Ivanenko 2008; Song et al. 2011). Body lengths were measured from the anterior end of the body and along the curvature of the body to the posterior end. Descriptive terms generally followed (Ferrari 1995) and (Ferrari and Dahms 2007). Specimens of all six naupliar stages of Pseudocyclops sp. were deposited under USNM1153833 in the Smithsonian Institution's National Museum of Natural History (Suitland, MD, USA). Additional specimens were also retained by one of the authors (SC).

\section{Results}

NI (Figure 1A,B). Body has undivided length/depth of three specimens $83 / 69,86 / 71$, and $85 / 70 \mu \mathrm{m}$; posteriorly with one medial, dorsal seta. Antennule (Figure 2A): three segments with $0,1,1,1$ (all ventral), three terminal setae.

Antenna (Figure 3A): two-segmented protopod; coxa with one ventral seta, seta-like naupliar arthrite; basis with two ventral setae. Six-segmented exopod with $0,1,1,1,1$ (all ventral), two terminal setae. Endopod two-segmented with one ventral, two terminal setae.

Mandible (Figure 4A): two-segmented protopod; coxa with one ventral seta; basis with two ventral setae. Exopod four-segmented with 1, 1, 1 (all ventral), two terminal setae. Endopod two-segmented; proximal segment with two ventral setae and distal segment with two terminal setae.

NII (Figure 1C). Differs from NI as follows: body is divided by a simple groove into anterior and posterior sections; length/depth of three specimens 99/75, 100/81, and $100 / 81 \mu \mathrm{m}$.

Antennule (Figure 2B): five segments with $0,1,1,1$ (all ventral), four terminal setae; no aesthetasc added to distal segment.

Antenna (Figure 3B): coxa with one ventral seta added distally to naupliar arthrite. Basis with two setae; six-segmented exopod with $0,1,1,1,1,2$ setae, and

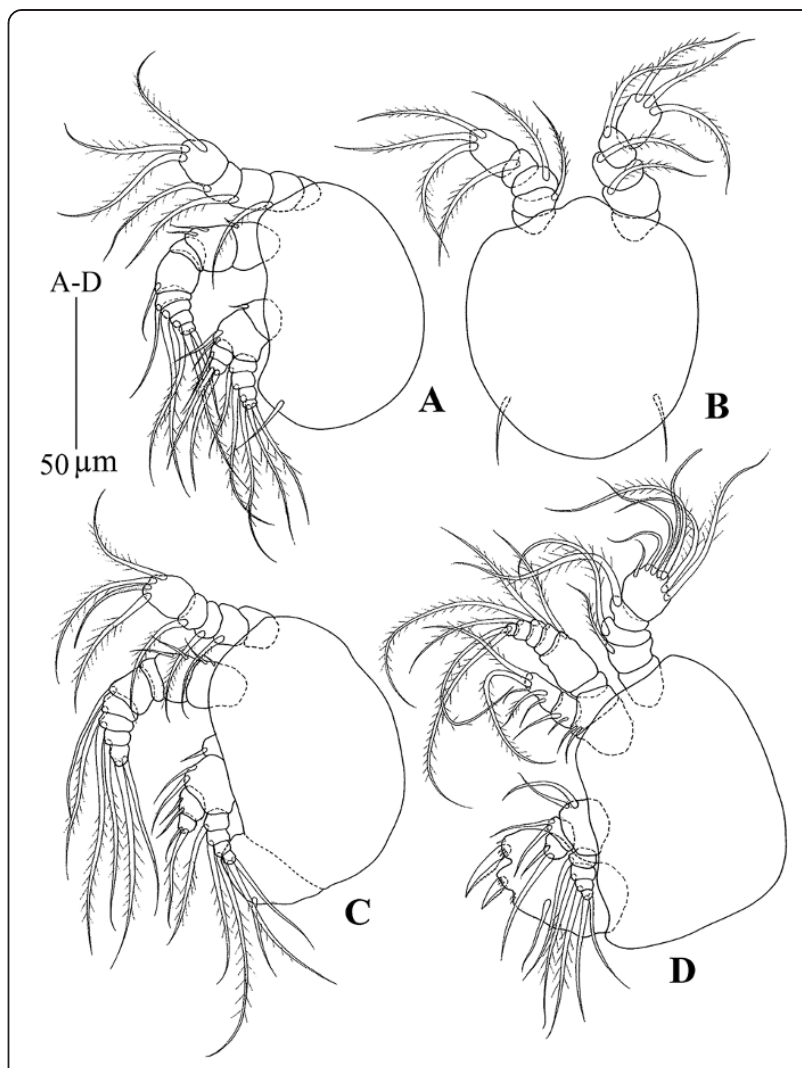

Figure 1 Pseudocyclops sp. naupliar stages. (A) NI in lateral view. (B) NI in dorsal view. (C) NII in lateral view. (D) NIV in lateral view.

two-segmented endopod with two setae, not one and three setae (one ventral, two terminal), not two.

Mandible (Figure 4B): both segments of endopod shorter and broader, proximal segment with two setae, not one seta. Exopod unchanged.

NIII (Figure 1D). Differs from NII as follows: length/ depth of two specimens $99 / 73$ and $102 / 73 \mu \mathrm{m}$. Short, thick, dorsal setal pair and small spinules posterior to medial-dorsal seta; each bud of caudal ramus with one thick seta.

Antennule (Figure 2C): antepenultimate segment short; terminal segment broader with one ventral and two dorsal setae and one terminal aesthetasc.

Antenna (Figure 3C): two-segmented endopod, proximal segment with two and distal segment with five ventral setae, not three setae.

Mandible (Figure 4C): proximal endopodal segment with three ventral setae.

Maxillule (Figure 5A): unilobed bud with one seta.

NIV (Figure 6A). Differs from NII as follows: length/ depth of three specimens 142/92, 144/92, and 152/ $98 \mu \mathrm{m}$. Three pairs of short, thick dorsal setae posterior to medial-dorsal seta, not one pair; each bud of caudal ramus with two thick setae, not one seta. Antennule (Figure 2D): with two ventral setae, not one 


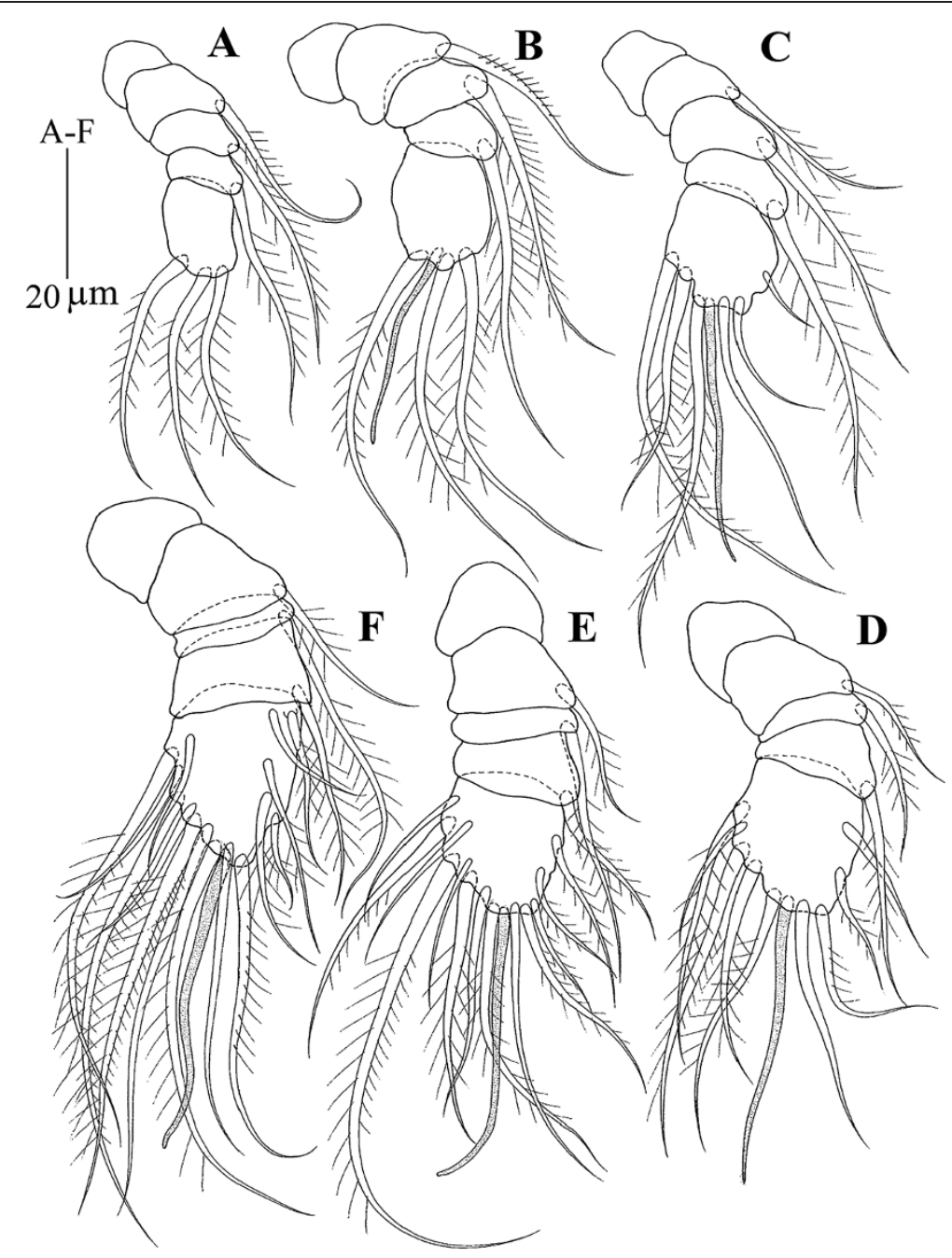

Figure 2 Pseudocyclops sp. right antennules of naupliar stages in anterior view. (A) NI. (B) NII. (C) NIII. (D) NIV. (E) NV. (F) NVI.

seta, on terminal segment and four dorsal setae, not two setae.

Antenna (Figure 3D): basis with four setae, not two. Six-segmented exopod with 0, 3 (only showing two in Figure 3D), 1, 1, 1, 3, not 2, on distal segment.

Mandible (Figure 4D): coxa with elongated ventral gnathobase with three ventral tooth-like attenuations; basis with four setae, not two. Proximal endopodal segment with three dorsal setae, not two ventral setae; distal segment oriented ventrally with four setae, not two setae.

Maxillule (Figure 5B): complex bud with three thick rounded terminal setae, one thick rounded ventral seta, and three thin ventral setae. Thick rounded setae with longer, thicker setules distally and shorter setules proximally.

$N V$ (Figure 6B). Differs from NIV as follows: length/ depth of four specimens 156/100,160/103, 165/105, and $169 / 105 \mu \mathrm{m}$. Short, thick setal pair added laterally.

Antennule (Figure 2E): with three ventral setae, not two setae, on terminal segment and seven dorsal setae, not four setae. Each small, thin dorsal seta juxtaposed to longer, thicker seta.

Antenna (Figure 7A): terminal endopodal segment with seven setae not five. Exopodal segments with 0, 3, 1, 1, 1, 3 setae, not 0,2 .

Mandible (Figure 4E): basis with five ventral setae not three.

Maxillule (Figure 5C): with four thick rounded ventral setae, not three setae.

NVI (Figure 8). Differs from NVI as follows: length/ depth of three specimens 174/107, 192/111, and 214/ $113 \mu \mathrm{m}$.

Antennule (Figure 2F): five ventral setae, not three setae.

Antenna (Figure 7B): distal endopodal segment with eight setae (three lateral, five terminal), not seven setae. Exopodal segments with 0, 4, 1, 1, 1, 3 setae, not 0, 3 .

Mandible (Figure 4F): coxal gnathobase slightly elongate, but rounded ventrally, without attenuations. Proximal 


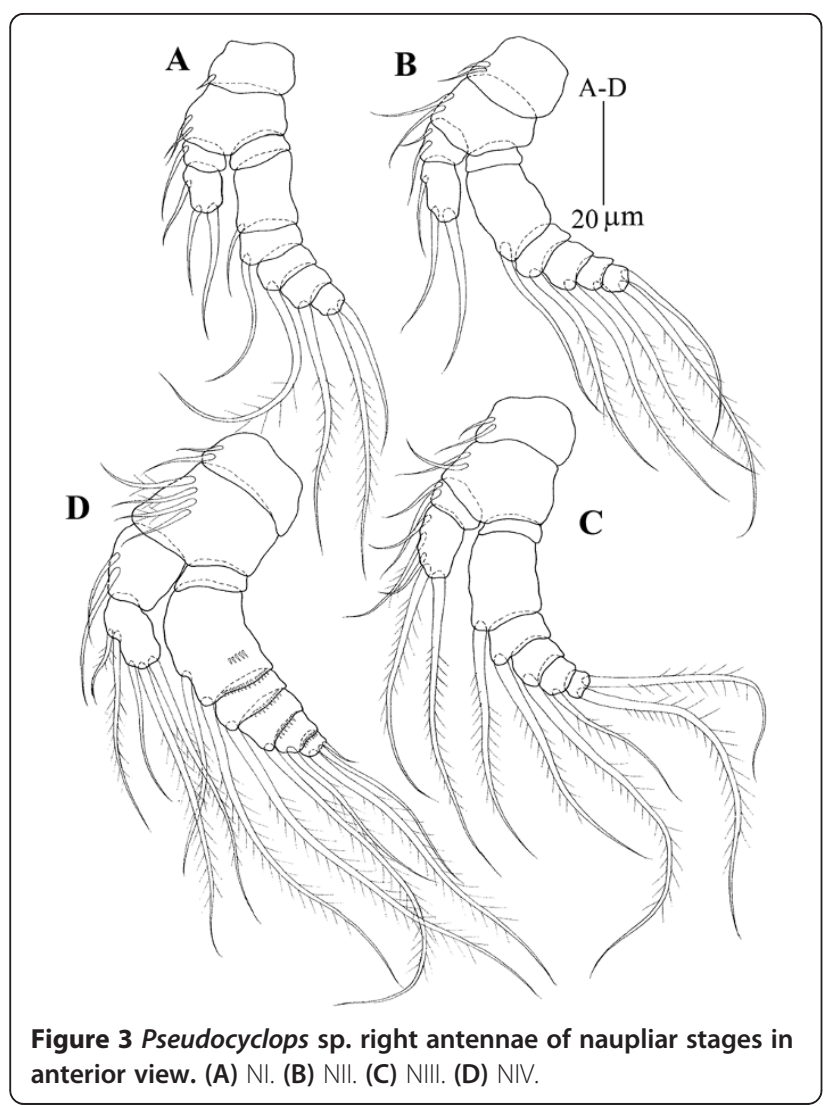

endopodal segment with one ventral seta, not five dorsal setae; distal segment oriented distally with six setae (two ventral, four terminal), not four setae.

Maxillule (Figure 5D): multilobed bud; basal part with three short ventral setae; dorsal lobe with one seta; distodorsal lobe with four thick rounded terminal setae and one simple dorsal seta; distoventral lobe with three terminal and three ventral setae; ventral lobe with one seta.

Maxilla (Figure 9A): elongated bud with seven groups of $1,2,2,2,2,2,5$ setae; one seta of the sixth group distinctively thickened.

Maxilliped (Figure 9B): elongate bud with two setae.

Leg 1 (Figure 9C): bilobed bud with four attenuations on dorsal lobe and three attenuations on ventral lobe.

Leg 2 (Figure 9D): bilobed bud with two attenuations on dorsal lobe and two attenuations on ventral lobe.

Variability: specimens of NIII were without an aesthetasc on the terminal antennular segment but still had seven setae in total.

\section{Discussion}

Six naupliar stages were recovered from this Pseudocyclops population as described by (Chullasorn et al. 2010) that inhabits aquaria at the John G. Shedd Aquarium (Chicago, IL, USA). Six naupliar stages are also known

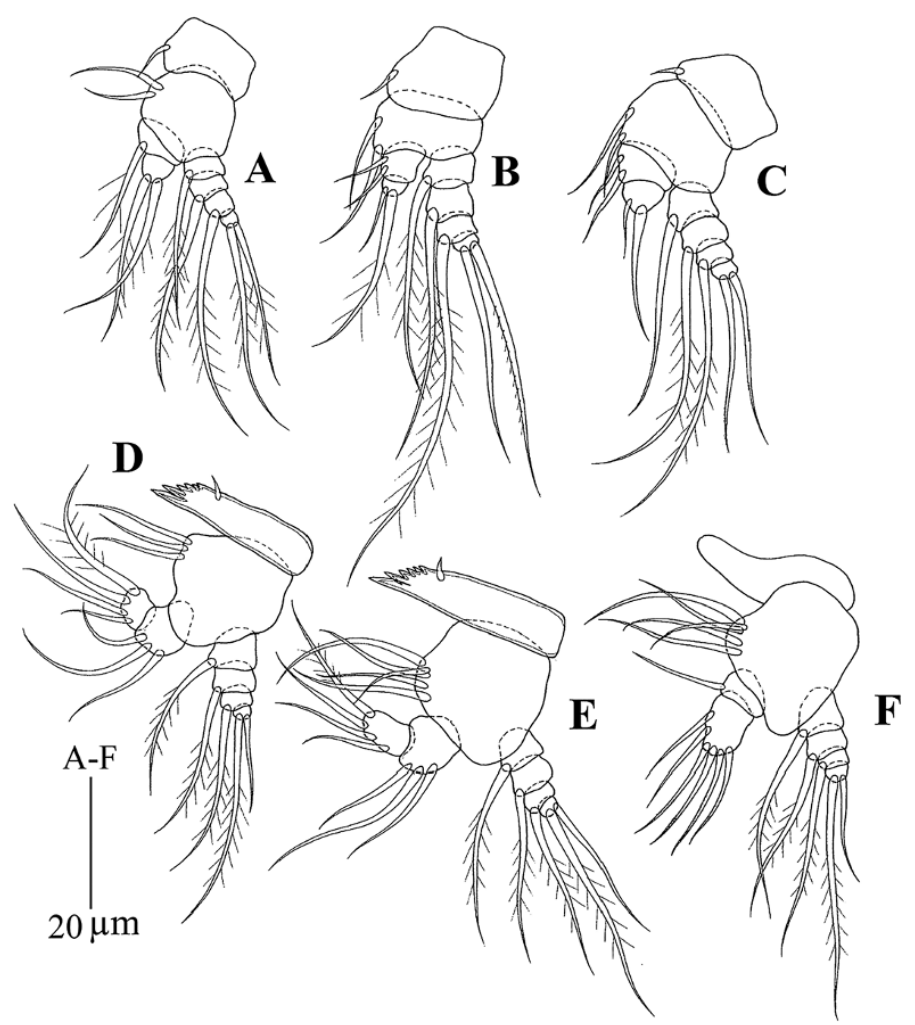

Figure 4 Pseudocyclops sp. right mandible of naupliar stages in anterior view. (A) NI. (B) NII. (C) NIII. (D) NIV. (E) NV. (F) NVI. 


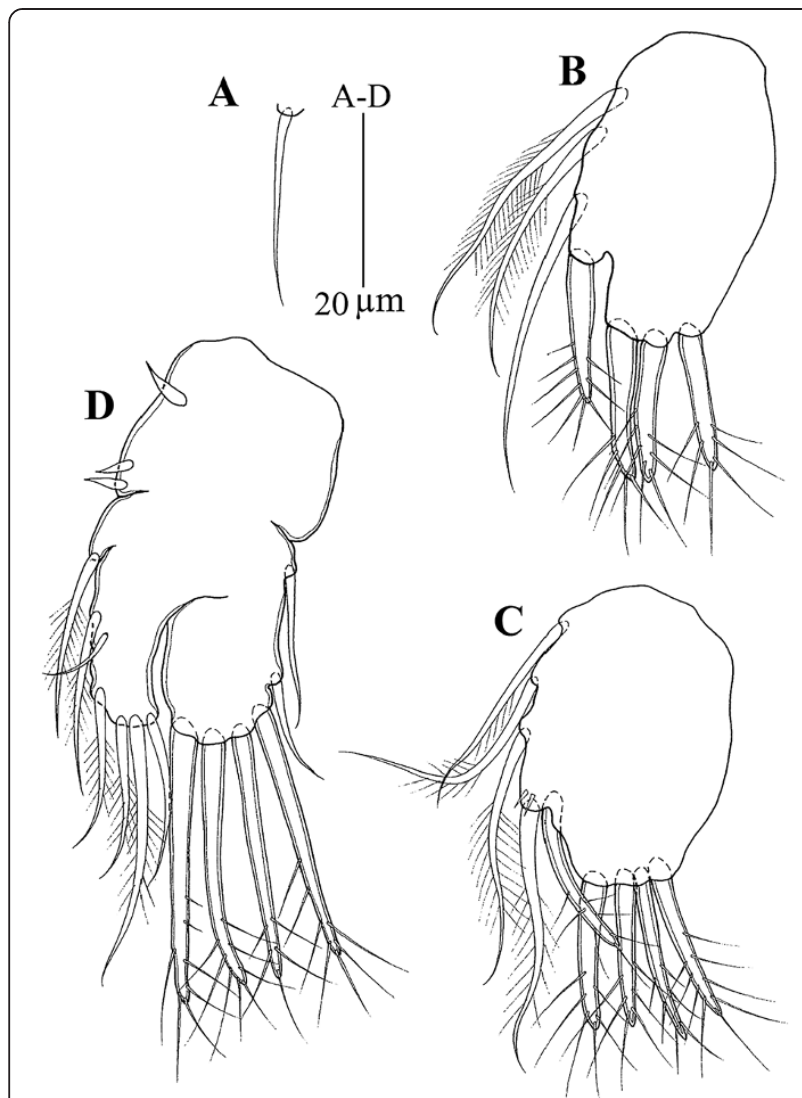

Figure 5 Pseudocyclops sp. left maxillules of naupliar stages in anterior view. (A) NIII. (B) NIV. (C) NV. (D) NVI.

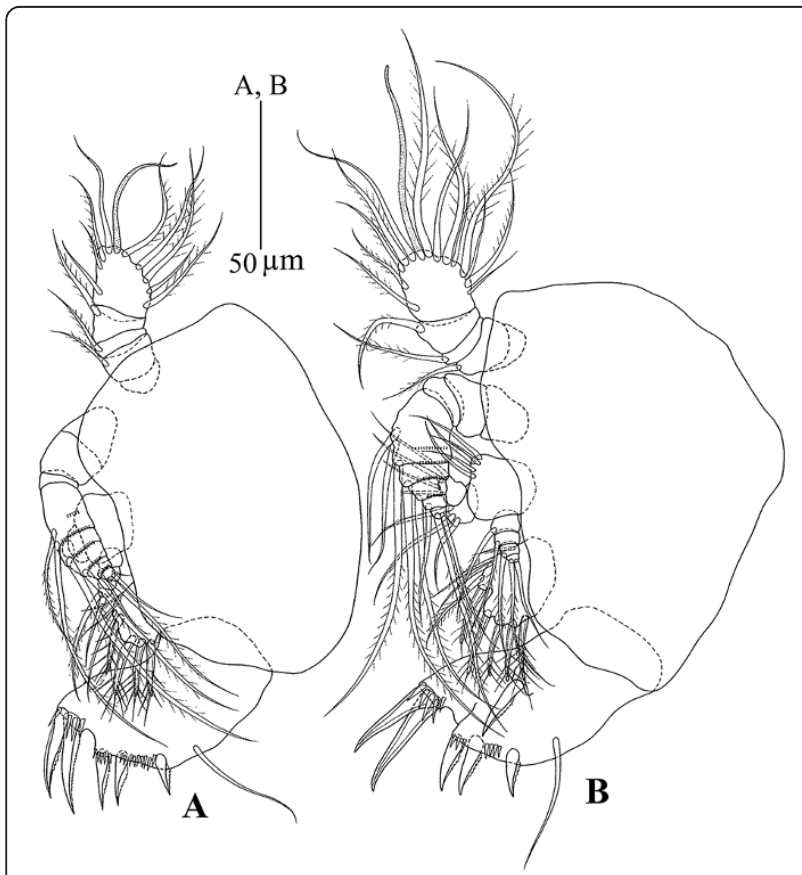

Figure 6 Pseudocyclops sp. naupliar stages: (A) NIV in lateral view and (B) NV in lateral view.

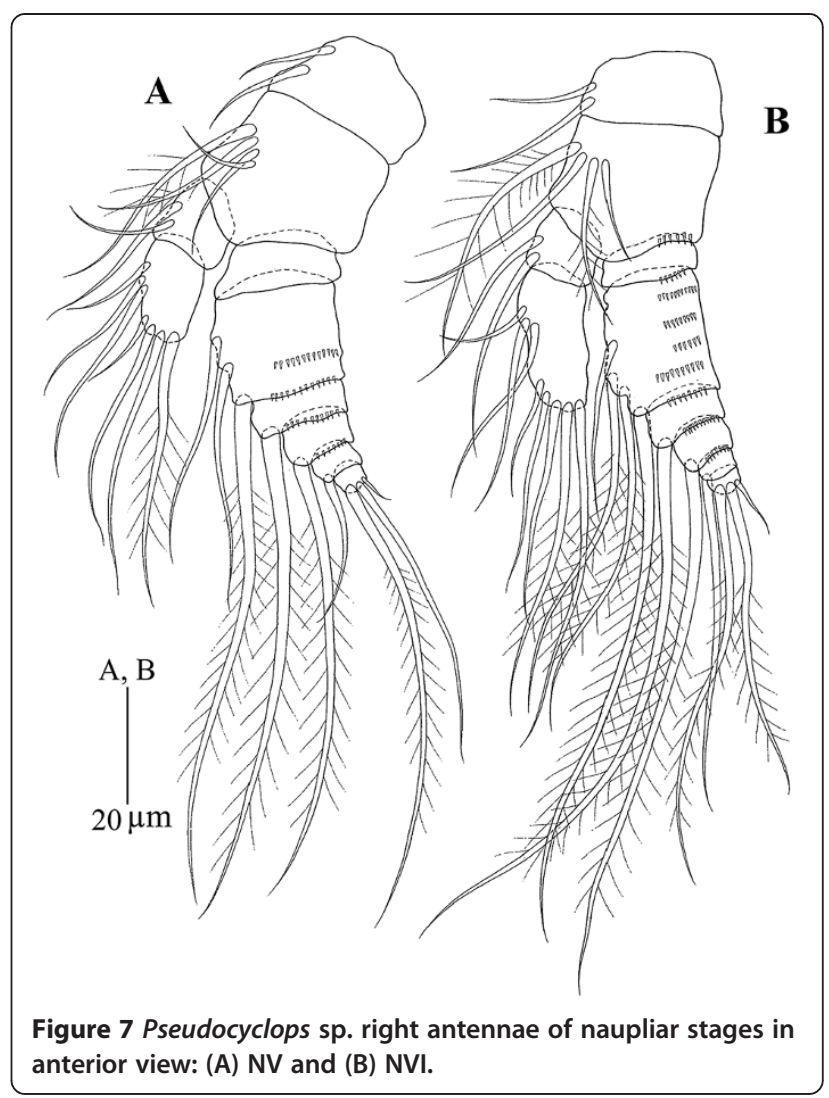

for Pseudocyclops umbraticus (Costanzo et al. 2004). In contrast to Pseudocyclops sp., the naupliar stages of P. umbraticus appear to have more segmental and setal elements than Pseudocyclops sp. However, interpreting the exoskeletal morphology of juvenile specimens of any Pseudocyclops may be difficult because the nauplii of these species appear to molt quickly from one stage to the next. Thus, the exoskeleton of the subsequent stage can often be seen within the cuticle of the specimen under examination. For example, swimming legs 1 and 2 of $P$. umbraticus appear to be segmented limbs (Costanzo et al. 2004), although this configuration is usually reported at the first copepodid stage of other copepods.

At NI, the naupliar body of Pseudocyclops sp. is simple, almost circular dorsally, and laterally slightly pointed posteriorly; a pair of simple setae presumably belong to the bud of the caudal rami. During NII to NVI, the body is separated into a deep anterior section and a shallow posterior section; the pair of setae is now dorsal on the posterior section. Two pairs of dorsolateral spine-like setae are added to the posterior section at NIII, and three more pairs are added at NIV; a lateral pair is added at NV. All of these spine-like setae are posterior and ventral to the simple seta. The posterior body never bears buds of any limb except the caudal ramus; it is presumed to represent the anal segment of the copepod. Spine-like 


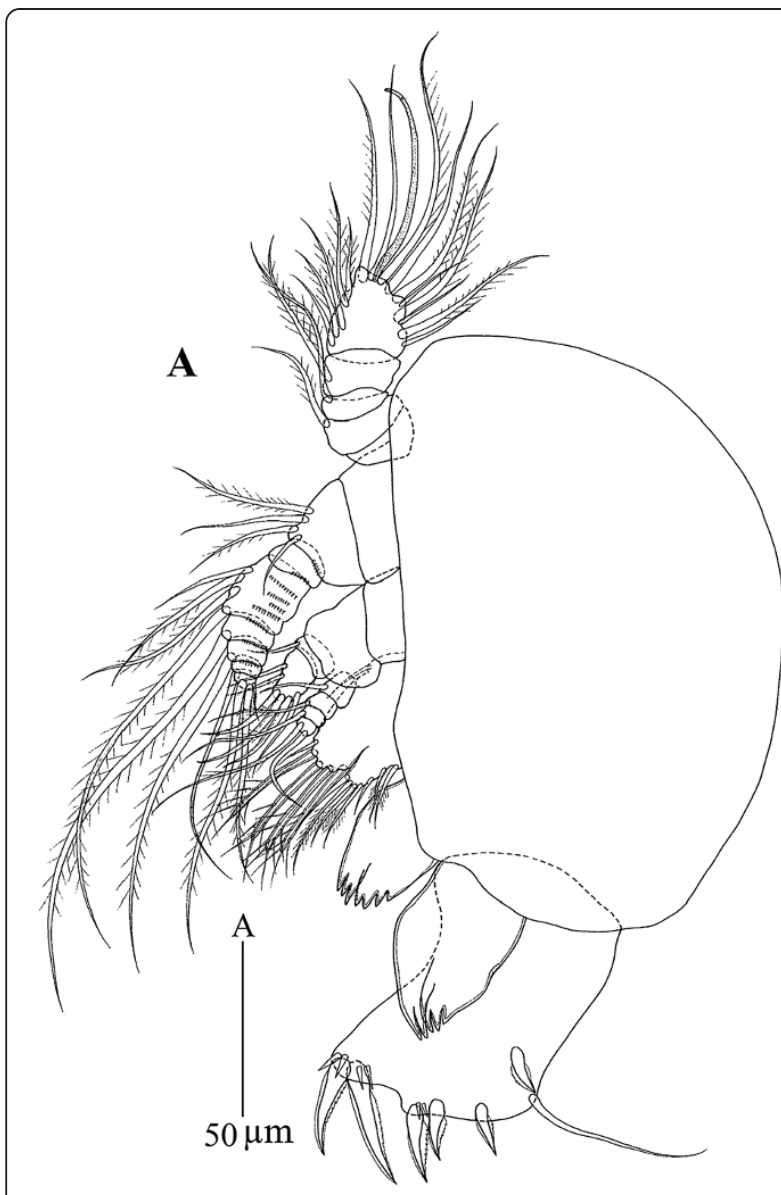

Figure 8 Pseudocyclops sp. naupliar stages: NVI in lateral view.

setae are those of the bud of the caudal ramus, and at least one of the seven pairs of setae present on NVI will not have a successor among the six setae on the caudal ramus of CI (see Ferrari et al. 2011b). The naupliar body of calanoid copepods like Pareuchaeta norvegica (Boeck 1872) and Chirideus armatus (Boeck 1872) does not elongate during development (Nicholls 1934; Matthews 1964). The naupliar body of centropagoideans does elongate posteriorly, but this posterior section is not distinctly separate, nor does it bear spine-like setae (e.g., see Lawson and Grice 1970; Grice 1971; Grice and Gibson 1982). A distinctly separate posterior section of the naupliar body with spine-like setae is present on calanoids like Eucalanus bungi bungi Giesbrecht 1893, Parvocalanus crassirostris (Dahl 1894), Neocalanus tonsus (Brady 1883), Calanoides macrocarinatus Brodsky 1957, and Calanus australis Brodsky 1959 (see Johnson 1937; Lawson and Grice 1973; Bradford et al. 1988). However, spine-like setae on these calanoids are ventral or lateral, not dorsal or lateral, as is the case for Pseudocyclops sp. The structure and setation of this posterior section of the body are unique among calanoids.

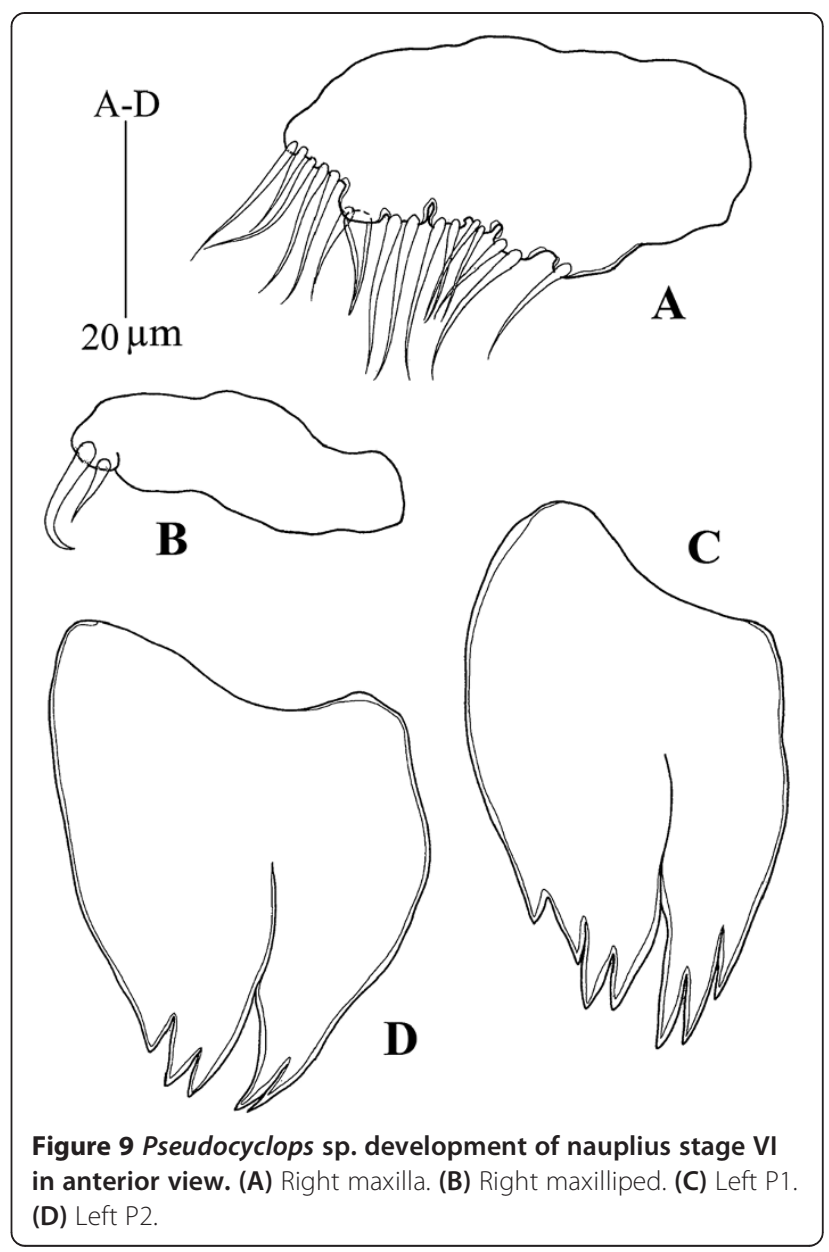

The antennule is five-segmented throughout naupliar development; most copepods, including all gymnoplean calanoids, have no more than three segments; polyarthran podopleans, with five- or six-segmented antennules, are the only copepods with more than three segments. Setae are added dorsally and ventrally to the distal segment beginning with the molt to NIII, as is the usual case for calanoids. Each of the 19 setae on the antennule of NVI may have a successor among the 20 setae on the antennules of $\mathrm{CI}$ with the element being the proximal aesthetasc of CI (see Ferrari et al. 2011a).

A simple, seta-like structure on the coxa of the antenna of all naupliar stages was inferred to be the naupliar arthrite (see Ferrari and Dahms 2007) that is lost during the molt to CI (see Ferrari et al. 2011b). On the segment adjacent to the unarmed proximal exopodal segment of the antenna, setae are added proximally to the proximal seta of the previous stage during molts to NIV NVI; this is consistent with the model of segmental patterning of this ramus proposed by Ferrari and Dahms (2007). It should be noted that patterning of this limb continues through copepodid phase development, 
and this attribute is apomorphic for these pseudocyclopids (Ferrari et al. 2011a).

A gnathobase is added to the coxa of the mandible during the molt to NIV, as is generally true for gymnoplean calanoids, but ventral attenuations of the gnathobase are lost during the molt to NVI; they are again well-developed at CI. Although the mandibular gnathobases may fail to form during the naupliar phase and are present only during the copepodid phase of development of calanoids like Pareuchaeta norvegica (see Nicholls 1934), the loss of the tooth-like attenuations is unique to Pseudocyclops. The setae on the proximal endopodal segment of the mandible originate dorsally at stages NIV and NV, rather than ventrally as they do at stages NI III and NVI. These changes were correlated with the change in orientation of the distal endopodal segment which appears to originate ventrally on the proximal segment of NIV and $\mathrm{NV}$, rather than distally on the proximal segment of NI $\sim$ III and NVI. These changes have not been reported for any other calanoid, and the morphological restoration at NVI is particularly noteworthy.

The maxillule of Pseudocyclops sp. begins development at NIII as a simple bud with one seta, and the limb becomes a complex bud with many more setae at later naupliar stages (Ferrari and Dahms 2007). This follows a general calanoid pattern. However, thick setae on the maxillule appear to be unique and are not present on copepodids (Ferrari et al. 2011a). Buds of maxilla of Pseudocyclops sp. initially appear at NVI, one stage later than is usual for calanoids; buds of the maxilliped and swimming legs 1 and 2 initially appear at NVI, which is the usual timing (Ferrari and Dahms 2007).

The issue of how many attributes are expressed by nauplii of species of Pseudocyclops may be shared with nauplii of related gymnopleans is compromised by two factors. First, there is no consensus about the relationship of species of Pseudocyclops to other basal gymnopleans, namely of the Epacteriscoidea, Platycopioidea, Augaptiloidea, Bathypontioidea, or Boholinidae (BradfordGrieve et al. 2010, Ferrari et al. 2011a). Second, regardless of the phylogenetic hypothesis, naupliar development is unknown for those groups of interest.

\section{Conclusions}

Given the lack of information on naupliar development among the Copepoda, the here presented naupliar development and discussion of Pseudocyclops sp. is a valuable addition to our knowledge, particularly since the development is known for only one other species of the calanoid taxon Pseudocyclopidae as yet. Many of the here reported ontogenetic changes have not been reported for any other calanoid. The morphological restoration at NVI is particularly interesting.
Competing interests

The authors declare that they have no competing interests.

\section{Authors' contributions}

FDF was the principal investigator and contributed most of the discussion in this manuscript. HUD contributed to the discussion of phylogenetic findings. SC contributed to most of the writing. PK made most of the morphological documentation. MS provided the specimens and initiated the study. All authors read and approved the final manuscript.

\section{Acknowledgements}

This research was financially supported by a grant from the National Research Foundation (NRF) of Korea funded by the Korean Government (MEST) (NRF-2010-0025412) given to HUD. This research was a part of the project titled 'Development of Korea Operational Oceanographic System' and 'Long-term Change of Structure and Function in Marine Ecosystems of Korea' funded by the Ministry of Land, Transport and Maritime Affairs, Korea. This work formed part of Korea Ocean Research and Development Institute Projects (PK07920, PE98811, and PE98747).

\section{Author details}

11826 Deer Dr., McLean, VA 22101, USA. ${ }^{2}$ Green Life Science Department, College of Convergence, Sangmyung University, 7 Hongij-dong, Jongno-gu, Seoul 110-743, Republic of Korea. ${ }^{3}$ Department of Biology, Faculty of Science, Ramkhamhaeng University, Bangkok 10240, Thailand. ${ }^{4}$ John G. Shedd Aquarium, 1200 S. Lake Shore Drive, Chicago, IL 60605, USA.

Received: 5 June 2013 Accepted: 17 September 2013

Published: 5 December 2013

\section{References}

Andronov VN (1986) Bottom Copepoda in the area of Cape Blanc (Islamic Republic of Mauretania). The family Pseudocyclopidae. Zool Zhurnal 65(3):456-462 (in Russian with English summary)

Barr DJ (1994) The taxonomy, phylogeny and zoogeography of the demersal copepod genus Pseudocyclops (Crustacea: Copepoda: Calanoida) of the world. Thesis, Texas A\&M University College Station

Baviera C, Crescenti N, Zagami G (2007) Pseudocyclops costanzoi, a new species (Copepoda, Calanoida, Pseudocyclopidae) from the Mediterranean Sea, Faro Lake, Sicily. Crustaceana 80(5):569-576

Bowman TE, González JG (1961) Four new species of Pseudocyclops (Copepoda: Calanoida) from Puerto Rico. Proc US Natl Mus 113(3452):37-59

Bradford JM, Ohman MD, Jillett JB (1988) Larval morphology and development of Neocalanus tonsus, Calanoides macrocarinatus, and Calanus australis (Copepoda: Calanoida) in the laboratory. NZ J Mar Freshw Res 22(3):301-320

Bradford-Grieve JM, Boxshall GA, Ahyong ST, Ohtsuka S (2010) Cladistic analysis of the calanoid Copepoda. Invert Systemat 24:291-321

Brady GS (1872) A list of the non-parasitic marine Copepoda of the north-east coast of England. Nat His Trans Northumb Dur 4:423-445. pls. 17-21

Brugnano C, Guglielmo L, lanora A, Zagami G (2009) Temperature effects on fecundity, development and survival of the benthopelagic calanoid copepod, Pseudocyclops xiphophorus. Mar Biol 156(3):331-340

Brugnano C, Celona A, Zagami G (2010) A new species of Pseudocyclops (Copepoda: Calanoida) from Lake Faro (central Mediterranean Sea). Vie Milieu 60(1):1-7

Chullasorn S, Ferrari FD, Dahms H-U (2010) Pseudocyclops schminkei (Copepoda, Calanoida, Pseudocyclopidae), a new species from Okinawa. Helg Mar Res 64:35-52

Costanzo G, Crescenti N, Zagami G (2004) Postembryonic development of Pseudocyclops umbraticus Giesbrecht, 1893 (Copepoda, Calanoida) from coastal waters of Sicily. Crustaceana 77:49-66

Dahms H-U, Chullasorn S, Schizas NV, Kangtia P, Anansatitporn W, Yang W-X (2009) Naupliar development among Tisbidae (Copepoda: Harpacticoida) with a phylogenetic analysis and naupliar description of Tisbe thailandensis from Thailand. Zool Stud 48(6):780-796

Ferrari FD (1995) Six copepodid stages of Ridgewayia klausruetzleri, a new species of calanoid copepod (Ridgewayiidae) from the barrier reef in Belize, with comments on appendage development. Proc Biol Soc Wash 108:180-200

Ferrari FD, Dahms H-U (2007) Post-embryonic development of the Copepoda. Crust Monogr 8:i-vi:1-226 
Ferrari FD, Ivanenko VN (2008) Identity of protopodal segments and the ramus of maxilla 2 of copepods (Copepoda). Crustaceana (Leiden) 81(7):823-835

Ferrari FD, Chullasorn S, Dahms H-U (2011a) Immature copepodids of Pseudocyclops schminkei (Copepoda, Calanoida) and the relationship of Pseudocyclopidae to other calanoids. Crust Monogr 16:149-176

Ferrari FD, Ivanenko VN, Dahms H-U (2011b) Body architecture and relationships among basal copepods. J Crust Biol 30(3):465-477

Grice GD (1971) The developmental stages of Eurytemora americana Williams, 1906, and Eurytemora herdmani Thompson \& Scott, 1897 (Copepoda, Calanoida). Crustaceana (Leiden) 20(2):145-158

Grice GD, Gibson VR (1982) The developmental stages of the calanoid copepod Labidocera wollastoni (Lubbock) with observations on its eggs. Cahiers Biol Mar 23(2):215-225

Johnson MW (1937) The developmental stages of the copepod Eucalanus elongatus Dana var. bungii Giesbrecht. Trans Am Microscop Soc 56:79-98

Lawson TJ, Grice GD (1970) The developmental stages of Centropages typicus Krøyer (Copepoda, Calanoida). Crustaceana (Leiden) 18(2):187-208

Lawson TJ, Grice GD (1973) The developmental stages of Paracalanus crassirostris Dahl, 1894 (Copepoda, Calanoida). Crustaceana (Leiden) 24(1):43-56

Matthews JBL (1964) On the biology of some bottom-living copepods (Aetideidae and Phaennidae) from western Norway. Sarsia 16:1-46

Nicholls AG (1934) The developmental stages of Euchaeta norvegica. Boeck Proc Roy Soc Edinb 54:31-50

Song SJ, Dahms H-U, Khim JS (2011) Postembryonic development of Amenophia orientalis (Copepoda, Harpacticoida) with a review on thalestridomorph development. Proc Biol Soc Wash 124(4):341-357

doi:10.1186/1810-522X-52-51

Cite this article as: Ferrari et al: Naupliar development of Pseudocyclops sp. (Copepoda: Calanoida: Pseudocyclopidae): description of an unusual set of character states. Zoological Studies 2013 52:51.

\section{Submit your manuscript to a SpringerOpen ${ }^{\circ}$ journal and benefit from:}

- Convenient online submission

- Rigorous peer review

- Immediate publication on acceptance

- Open access: articles freely available online

- High visibility within the field

- Retaining the copyright to your article

Submit your next manuscript at $\gg$ springeropen.com 